\title{
Importance to Know the Long-Term Outcome after Endovascular Therapy with Bare Metal Stent Implantation for Femoropopliteal Artery Disease
}

\author{
Naruhiko Ito
}

Division of Cardiology, Yokosuka Kyosai Hospital, Kanagawa, Japan

\section{See article vol. 29: 000-000}

Bare nitinol stent implantation for peripheral artery disease has been widely used as an optimal treatment. Now we can choose several devices for endovascular therapy, namely, bare nitinol stent, drugcoated balloon, or drug-eluting stent. The primary patency of endovascular therapy with a drug-coated balloon was significantly higher than a standard balloon ${ }^{1-3)}$. We can perform endovascular therapy using a drug-coated balloon as a finalized device without stent implantation in optimal cases. However, stent implantation was required when unacceptable arterial dissection was induced using balloon dilatation, or residual stenosis was unacceptable after balloon dilatation. In cases that required stent implantation, using a drug-eluting stent has been recently increasing because of the superior primary patency to a bare nitinol stent ${ }^{4-5}$. However, a bare nitinol stent had been a standard finalized device of endovascular therapy before drug-eluting device era. Until now and from now on we must follow up on many patients who had undergone endovascular therapy with bare-metal stent implantation. It is important for us to understand the long-term prognosis after endovascular therapy with bare nitinol stent implantation to allocate optimal follow up and treatment. In recent study ${ }^{6}$, the rate of recurrent in-stent restenosis was significantly lower in patients treated with drug-coated balloon angioplasty for superficial femoral artery in-stent restenosis than patient treated with standard balloon angioplasty. Many patients treated with bare nitinol stent implantation have experienced in-stent restenosis in long-term period, but now we can choose a new device to treat in-stent restenosis of bare nitinol stents, namely, a drug-coated balloon.

Recent study reported $^{7)}$ association between tissue characteristics assessed with optical coherence tomography and outcome after percutaneous coronary intervention for in-stent restenosis lesions. The rate of recurrent in-stent restenosis of lesions with a homogeneous structure was significantly higher in patients treated with standard balloon angioplasty than patients treated with drug-coated balloon angioplasty or drug-eluting stent implantation. Alternatively, there were no significant differences in the rate of recurrent in-stent restenosis of lesions with a heterogeneous structure between patients treated with standard balloon angioplasty, drug-coated balloon angioplasty, and drug-eluting stent implantation. In peripheral artery disease, an association between outcomes after endovascular therapy and lesion characteristics assessed using imaging devices has not been analyzed enough. It will be required to confirm the integrity between lesion characteristics of in-stent restenosis assessed using imaging devices and optimal treatment.

Dr. Soga et al reported ${ }^{8)}$ long-term outcome after endovascular therapy with bare nitinol stent implantation for femoropopliteal artery disease in the current paper. Primary patency rapidly decreased during the first year, and continued to decrease gradually after that. Recent pathological study ${ }^{9}$ reported that early stent failure occurred commonly due to not neoathelosclerosis but thrombosis. Causes of early stent failure and late stent failure may be different. Recent study ${ }^{10)}$ reported that flow velocity of femoropopliteal artery after endovascular therapy affected primary patency. Low flow velocity due to insufficient stent enlargement, edge dissection, and poor runoff vessels below the knee may induce early stent failure due to stent thrombosis. The current

Address for correspondence: Naruhiko Ito, Division of Cardiology, Yokosuka Kyosai Hospital, 1-16, Yonegahama-Dori, Yokosuka-Shi, Kanagawa-Ken, 2388558, Japan E-mail: nito0516@yahoo.co.jp

Received: January 17, 2022 Accepted for publication: January 18, 2022

Copyright@2022 Japan Atherosclerosis Society

This article is distributed under the terms of the latest version of CC BY-NC-SA defined by the Creative Commons Attribution License. 
paper is the first to report that evaluated timedependent risk factors of patency loss. Several factors, namely female sex, age $>80$ years, diabetes mellitus, dialysis-dependent renal failure, chronic limbthreatening ischemia, chronic total occlusion, lesion length $>20 \mathrm{~cm}$, and reference vessel diameter $<4$ $\mathrm{mm}$, was significantly associated with an increasing risk of patency loss immediately after stent implantation, whereas the prognostic impact of age $>$ 80 years and chronic limb-threatening was significantly attenuated afterward. The analysis for the reason why age $>80$ years and chronic limbthreatening ischemia worsen long-term limb patency and the mechanism is required.

\section{Conflicts of Interest}

None.

\section{References}

1) Laird JR, Schneider PA, Tepe G, Brodmann M, Zeller T, Metzger C, Krishnan P, Scheinert D, Micari A, Cohen DJ, Wang H, Hasenbank MS, Jaff MR, IN.PACT SFA Trial Investigators. Durability of Treatment Effect Using a Drug-Coated Balloon for Femoropopliteal Lesions: 24-Months Results of IN.PACT SFA. J Am Coll Cardiol, 2015; 66: 2329-2338

2) Rosenfield K, Jaff MR, White CJ, Singh KR, Hurtado CM, Metzger DC, Brodmann M, Pilger E, Zeller T, Krishnan P, Gammon R, Hülsbeck SM, Nehler MR, Bennati JF, Scheinert D, LEVANT 2 Investigators. Trial of a Paclitaxel-Coated Balloon for Femoropopliteal Artery Disease. N Engl J Med, 2015; 373: 145-153

3) Sachar R, Soga Y, Ansari MM, Kozuki A, Lopez L, Brodmann M, Schroë H, Ramanath VS, Cartelle JD, Zeller T, RANGER II SFA Investigators. 1-Year Results From the RANGER II SFA Randomized Trial of the Ranger Drug-Coated Balloon. JACC Cardiovasc Interv, 2021; 14: 1123-1133

4) Make MD, Ansel GM, Jaff MR, Odki T, Saxon RR, Smouse HB, Machan LS, Snyder SA, O'Leary EE, Rangheb AO, Zeller T, Zilver PTX Investigators. Durable
Clinical Effectiveness With Paclitaxel-Elutig Stents in the Femoropopliteal Artery: 5-Year Results of the Silver PTX Randomized Trial. Circulation, 2016; 133: 1472-1483

5) Gray WA, Keirse K, Soga Y, Benko A, Babaev A, Yokoi Y, Schroeder H, Prem JT, Holden A, Popma J, Jaff MR, Cartelle JD, Hülsbeck SM, IMPERIAL investigators. A polymer-coated, paclitaxel-eluting stent (Eluvia) versus a polymer-free, paclitaxel-coated stent (Zilver PTX) for endovascular femoropopliteal intervention (IMPERIAL): a randomized, non-inferiority trial. Lancet, 2018; 392: $1541-1551$

6) Krankenberg $H$, Tübler T, Ingwersen $M$, Schlüter $M$, Scheitert D, Blessing E, Sixt S, Kieback A, Beschorner U, Zeller T. Drug-Coated Balloon Versus Standard Balloon for Superficial Femoral Artery In-Stent Restensis: The Randomized Femoral Artery In-Stent Restenosis (FAIR) Trial. Circulation, 2015; 132: 2230-2236

7) Tada T, Kadota K, Hosogi S, Miyake K, Ohio M, Amano H, Izawa Y, Kanazawa T, Kubo S, Ichinohe T, Hyoudou Y, Hayakawa Y, Sabbah MMH, Otsuru S, Hasegawa D, Habara S, Tanaka H, Fuku Y, Kate H, Goto T, Mitsudo K. Association between tissue characteristics assessed with optical coherence tomography and mid-term results after percutaneous coronary intervention for in-stent restenosis lesions: a comparison between balloon angioplasty, paclitaxel-coated balloon dilatation, and drug-eluting stent implantation. Eur Heart J Cardiovasc Imaging, 2015; 16: 1101-1111

8) Soga Y, Takahara M, Iida O, Suzuki K, Mori S, Kawasaki D, Haraguchi K, Yamaoka T, Ando K. Ten-Year Clinical Follow-Up Following Bare-Nitinol Stent Implantation for Femoropopliteal Artery Disease. J Atheroscler Thromb, 2021; Online ahead of print. doi: https://doi. org/10.5551/jat.63225

9) Kuntz SH, Torii S, Jinnouchi H, Cornelissen A, Sakamoto A, Sato Y, Kutyna M, Romero ME, Lejay A, Schwein A, Bonnin E, Finn AV, Chakfé N, Virmani R. Pathology and Multimodality Imaging of Acute and Chronic Femoral Stenting in Humans. JACC Cardiovasc Interv, 2020; 13: 418-427

10) Ito $N$, Hishikari $K$, Yoshikawa $H$, Tsujihata $S$, Abe $F$, Kanno Y, Iiya M, Murai T, Hikita H, Takahashi A, Yonetsu T, Sasano T. Angiographic flow velocity predicts lower limb outcomes after endovascular therapy: Application of the frame count method. Vasc Med, 2021; Online ahead of print 